\title{
The role of personal attitudes of control and responsibility for the uptake of peritoneal dialysis- a national survey among dialysis patients
}

\author{
Isabell Schellartz ${ }^{1 *}$, Tim Ohnhaeuser ${ }^{1}$, Thomas Mettang ${ }^{2}$ and Nadine Scholten ${ }^{1}$
}

\begin{abstract}
Background: Although most patients are suitable for both hemodialysis (HD) and peritoneal dialysis (PD), there seem to be differences in the outlook of patients who choose one modality over the other. There is currently limited literature about the impact of patients' personal attitudes on the decision for PD or HD. In this study, we tried to find out whether there were differences between patients who were on HD and PD in their desire for control and responsibility for their treatment.

Methods: The data were drawn from a nationwide postal survey of 630 HD and PD patients. Patients' desire for control was measured by scores on the internal locus of control (ILOC) scale. Patients were also asked how important taking responsibility for their dialysis had been for their treatment decision (ITR). Two multivariate logistic regression models, both adjusted for age, were applied to investigate whether there were differences between HD and PD patients in ILOC and ITR. Having one generic measure (ILOC) and one tailored to the dialysis context (ITR) gave the opportunity to investigate if it is a generic personality trait or rather a specific attitude that affects choice of dialysis modality.
\end{abstract}

Results: PD patients were younger and showed higher ILOC and ITR values. Multivariate logistic regression models adjusted for age confirmed the significant influence of ILOC and ITR on the uptake of PD. The odds ratios for being in the PD group were 1.53 for ILOC ( $p=0.030 ; 95 \% \mathrm{Cl} 1.04-2.25)$, 1.49 for ITR ( $p=0.019 ; 95 \% \mathrm{Cl} 1.07-2.07)$, and 0.95 ( $p=0.000 ; 95 \% \mathrm{Cl} 0.94-0.97$ ) for age in both models.

Conclusions: Our analysis shows the impact of personal attitudes on the uptake of PD. Participants who generally want to keep control of their lives and take responsibility for their dialysis treatment tended to choose PD. As PD is a home dialysis treatment that requires patients to participate and contribute, it is beneficial if patients' personalities support the treatment procedure. Having two completely different treatment options that suit to different personalities gives us the opportunity to consider the relationship between personal attitudes and choice of dialysis modality.

\footnotetext{
* Correspondence: ischella@web.de

'University of Cologne, Faculty of Human Sciences and Faculty of Medicine, Institute of Medical Sociology, Health Services Research and Rehabilitation Science (IMVR), Eupener Str. 129, 50933 Cologne, Germany

Full list of author information is available at the end of the article
}

(c) The Author(s). 2021 Open Access This article is licensed under a Creative Commons Attribution 4.0 International License, which permits use, sharing, adaptation, distribution and reproduction in any medium or format, as long as you give appropriate credit to the original author(s) and the source, provide a link to the Creative Commons licence, and indicate if changes were made. The images or other third party material in this article are included in the article's Creative Commons licence, unless indicated otherwise in a credit line to the material. If material is not included in the article's Creative Commons licence and your intended use is not permitted by statutory regulation or exceeds the permitted use, you will need to obtain permission directly from the copyright holder. To view a copy of this licence, visit http://creativecommons.org/licenses/by/4.0/. The Creative Commons Public Domain Dedication waiver (http://creativecommons.org/publicdomain/zero/1.0/) applies to the data made available in this article, unless otherwise stated in a credit line to the data. 


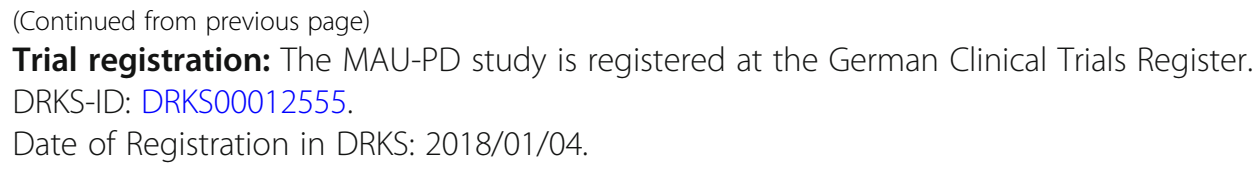

Keywords: Hemodialysis (HD), Peritoneal dialysis (PD), Treatment selection, Decision-making, Character, Personality, End-stage renal disease (ESRD), Renal replacement therapy, Desire for control

\section{Background}

Hemodialysis (HD) and peritoneal dialysis (PD) are considered equivalent options for the treatment of end-stage renal disease (ESRD) in terms of survival rates [1, 2]. Although it has been reported that patients with PD show better outcomes regarding their quality of life [3-5], Germany shows a low PD-ratio of 6\% [6]. The compulsory statutory health insurance (SHI) in Germany covers about $90 \%$ of the population [7]. This SHI reimburses both, in-center and home-based dialysis treatment options as well as the transport to the ambulatory dialysis center [8]. There is also a legal obligation to inform patients about different treatment options [9]. Looking at patient-related characteristics, the international literature shows, that due to only a few absolute contraindications against PD, most ESRD patients are eligible for both modalities $[10,11]$. Nevertheless, several studies have identified differences in educational level and gender between HD and PD patients [5, 12-15], and the majority of prior research indicates PD patients to be younger $[2,3,12-17]$. Other patient-related factors, like personality traits or attitudes, and their role in the context of dialysis modality choice have hardly been investigated.

One aspect of personality is the desire for control. If a person expects an event to be the result of his or her own behavior, this is called a belief in internal control. Hence, persons with a strong belief in internal control are convinced they determine events by their own knowledge and skills [18]. Among others, this desire for control has been used in medical-sociological research contexts to explain medical decisions or medical events [18-22].

There is limited, mainly qualitative evidence about the role of the desire for control in the context of dialysis patients. Studies have shown the relevance of the desire for control when making a decision on renal replacement therapies [23-25]. PD patients often suggest that control and autonomy were causal for their treatment choice $[26,27]$ whereas HD patients or former PD patients after the transition to HD reported a loss of control $[28,29]$. In addition, pre-dialysis patients emphasized their need to be personally responsible for their treatment decision-making process [30].

The aim of the present study is to investigate the impact of patients' desire for control and their view on the importance of taking responsibility for their own dialysis treatment on the decision for PD. Deepening existing qualitative examinations, the results contribute further insights through a representative quantitative survey using a validated instrument [19].

\section{Methods}

Survey

As the majority of the German population is contracted with SHIs [7], we collaborated with two large SHIs covering 6.6 million insurants [31, 32]. DAK-Gesundheit (Deutsche Angestellten-Krankenkasse) and SBK (Siemens Betriebskrankenkasse) selected adults ( $\geq 18$ years of age) who were dialyzing among their insurants. These insurants were contacted for a nationwide postal survey. The questionnaire, study information, and a franked envelope were prepared by the study group. Then the SHIs mailed them to their insurants at the end of 2018/beginning of 2019. The study group did not know the addresses of the insurants. Participants returned the completed questionnaire to the study group. Due to this anonymous survey design, the participants gave their informed consent to participate and publish the summarized results by completing and returning the questionnaire. Participants were informed about this procedure in the written study information. The procedure follows good clinical practice and the Declaration of Helsinki.

Through this procedure, 2095 patients were approached. After a one-time reminder, regardless of whether the survey had been completed by that time or not, 964 participants responded (46\% response rate). The survey was carried out as part of the MAU-PD study (German Clinical Trials Register ID: DRKS00012555), which aims to assess the reasons for the low PD ratio in Germany from different perspectives with a mixed-methods design [33].

\section{Measures}

In order to address the desire for control in the questionnaire, we used the validated 3-item short scale "Internal locus of control" (ILOC), which is based on the concept of belief in internal control [19]. The scale's three statements refer to the patient's level of taking responsibility, making decisions on their own, and ability to assert themselves, which were added up to a mean 
ILOC value. Answer categories were on a 5-point Likert scale from 1 "strongly disagree" to 5 "strongly agree". Due to their positive verbalization, high ILOC values indicate a strong belief in internal control [19]. We only calculated the ILOC scale means for participants who answered all 3 questions.

Besides this general attitude of a belief in internal control, respondents were explicitly asked how important it was for them to take responsibility for their decision regarding dialysis modality (ITR). This question was carried out from a number of items asking, "how important were the following aspects for your decision regarding dialysis modality?" For all of those items, we used an answer scale from 1 "not important at all" to 4 "very important". Because in this set of questions, aspects were mentioned that did not affect every participant (e.g., the opinion of relatives), an additional answer category of "not applicable" (N/A) was added. Hence, there was the 4-point Likert scale with the additional answer category N/A for ITR. These items were developed by the study group. Furthermore, participants were asked about their current dialysis modality, if the modality had changed in the past, and about sociodemographics like age, sex, and school education.

Having one generic measure (ILOC) and one tailored to the dialysis context (ITR) gives the opportunity to investigate both: Is there a generic personality trait or is it rather a specific attitude that affects the decision for PD choice of dialysis modality?

\section{Analysis}

This analysis aims to investigate the difference between in-center HD patients and PD patients (CAPD or CCPD). Focusing on the role of personal attitudes in decision-making for PD, we also categorized participants as PD patients who had initially decided for PD and then later changed from PD to HD. In order to compare effects of the general ILOC and the dialysis-specific ITR within the same study population, participants with missing values in one of these variables or those without information about their dialysis modality were excluded. Participants who stated that ITR was N/A were also excluded, because N/A is an alternative category to the remaining Likert scale, and it is not a direct answer to the question. For a reliability analysis, Cronbach's alpha was calculated for ILOC.

Univariate differences between HD and PD patients were analyzed regarding age, sex, and school education as well as ILOC and ITR. The comparison of the ILOC values of $H D$ and PD patients indicates whether there is a difference between those two groups regarding this generic personality trait; in contrast, ITR differences reflect whether there is a specific attitude, that is relevant for the decision for PD. Depending on the variables' nature and their distribution, Wilcoxon-Mann Whitney and Chi-square tests were used. Taking a possible confounder into account, age and ILOC were combined in a multifactorial logistic regression model for the dialysis modality group (HD or PD; Model A). In addition, the association of ITR and the dialysis modality group was examined and also adjusted for age (Model B). In order to investigate whether participants with a high desire for control also have a higher desire to take responsibility for their own dialysis treatment, a Spearman's rho correlation between ILOC and ITR was calculated. We also investigated ILOC differences between ITR responders and participants who ticked N/A with ITR to assess the external validity of our results.

Stata 16.1 was used for statistical computations.

\section{Results}

\section{Study population}

As shown in Fig. 1, 92 of the excluded patients did not answer ITR, and 153 chose N/A, of which 85 and 149 were HD patients, respectively.

A total of 630 dialysis patients were included in this analysis. Initially, 90\% $(n=565)$ started with in-center HD and $10 \%(n=65)$ started with PD (CAPD, CCPD). Of those patients who started with PD, 37 (57\%) later

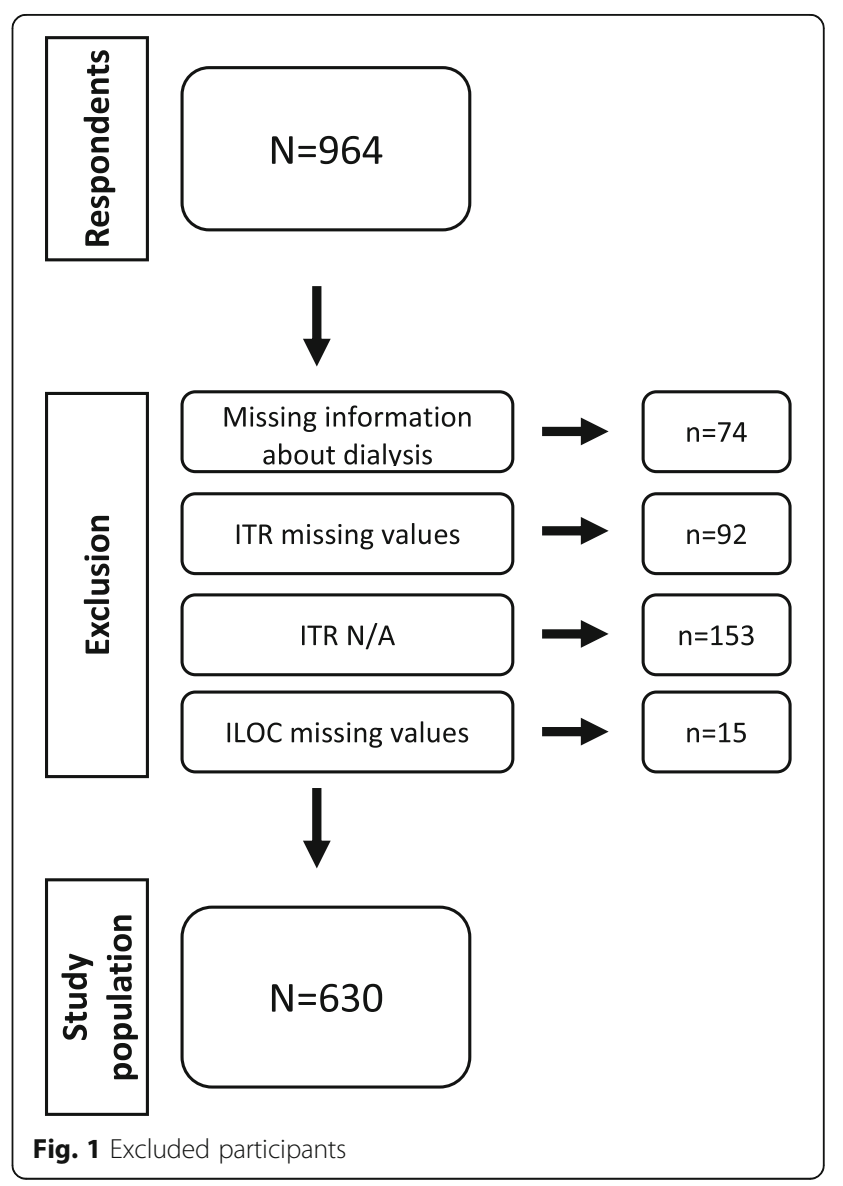


changed to in-center HD and one patient to home-based HD (2\%). At the time of the survey, the proportion of patients currently dialyzing via PD was $4.3 \%$. Participants were on average 68 years old (range of 22-96), and $40 \%$ were female. Table 1 provides further information about the study population. PD patients were significantly younger than HD patients. There were no differences regarding sex or level of school education between the HD and PD patients.

ILOC

Reliability analysis of ILOC revealed a Cronbach's alpha of 0.79. As displayed in Table 1, PD patients show a significantly higher ILOC than HD patients (4.3 vs. 4.0, $p=$ 0.020 ). As age was found to be the only sociodemographic confounder in our study, a multivariate logistic regression for modality choice (HD vs. PD) with ILOC and age as independent variables was built (Model A; see Table 2). In this model, both age and ILOC showed significant effects on the uptake of PD. The likelihood of being in the PD group was 5\% lower with every additional year of life $(p=0.000 ; 95 \%$ CI $0.94-0.97)$. With a one-point higher ILOC on the 5-point Likert scale, the likelihood of being in the PD group was 53\% higher $\left(p=0.030 ; 95 \%\right.$ CI 1.04-2.25). Pseudo $\mathbf{R}^{2}$ of Model A is 0.074 .

\section{ITR}

Taking responsibility for their treatment was rated as very important by $50 \%$ of the participants. For $6 \%$, this was not important at all. Table 1 shows the mean ITR values of HD and PD patients; Table 3 shows the distribution. On average, PD patients rated ITR higher than HD patients (3.5 vs. $3.2, p=0.010$ ). In particular, the percentage of participants who stated that taking responsibility was very important for them was higher in the PD group than in the HD group (66\% vs. $48 \%$ ). As age was found to be the only sociodemographic confounder in our study, another multivariate logistic regression for modality choice (HD vs. PD) with ITR and age as independent variables was built (Model B). Both age and ITR are significant in this model (see Table 2). The likelihood of being in the PD group decreased by $5 \%$ with every additional year of life ( $p=0.000 ; 95 \%$ CI $0.94-0.97)$. Patients who rated ITR one point higher on the 4-point answer scale had a $49 \%$ higher likelihood of being in the PD group ( $p=0.019 ; 95 \%$ CI 1.07-2.07). Pseudo $\mathrm{R}^{2}$ of Model B is 0.077 .

\section{ILOC and ITR}

Table 3 shows mean ILOC values depending on ITR answer categories. Spearman's rho of ILOC and ITR is 0.31 ( $p=0.000$ ), meaning $10 \%$ of the variability of both parameters is shared. As this study aims to investigate and quantify the impact of ILOC and ITR on the uptake of PD and there were limited opportunities for the adjustment of confounders, a combined model was not necessary to answer the research question.

Due to the high proportion of excluded participants who answered N/A in the ITR, a Wilcoxon-Mann Whitney test was conducted to investigate ILOC differences between N/A responders and our study population. Our study population stated higher ILOC values than N/A responders (4.1 vs. $3.8 ; p=0.007)$. Significantly more HD patients ticked N/A in the ITR $(p=0.003)$.

\section{Discussion}

Our study shows that the desire for control, operationalized by the ILOC scale, has a significant impact on the uptake of PD. Furthermore, the extent to which it is important for the participant to take responsibility for their own dialysis treatment (ITR) affects the decision for HD or PD. First, univariate tests show that ILOC and ITR vary significantly over HD and PD patients. Second, multivariate models with adjustment for age (Models A

Table 1 Participant characteristics

\begin{tabular}{llll}
\hline & HD $(\boldsymbol{n}=\mathbf{5 6 5})$ & PD $(\boldsymbol{n}=\mathbf{6 5})$ & Prob $>|\mathbf{z}|$ \\
\hline Age, mean (min-max) & $69(22-96)$ & $60(30-86)$ & 0.000 \\
Male, $\mathbf{n}$ (\%) & $343(61)$ & $36(55)$ & \\
School education, $\mathbf{n}(\%)$ & & \\
$\quad$ No school qualifications & $13(2)$ & $2(3)$ \\
$\quad$ Basic school qualification & $244(43)$ & $23(36)$ \\
$\quad$ Extended secondary school diploma & $193(34)$ & $25(39)$ \\
$\quad$ A-levels & $111(20)$ & $14(22)$ \\
ILOC, mean \pm std. dev. & $4.0 \pm 0.76$ & $4.3 \pm 0.68$ \\
Answer scale: 1-5 & $3.2 \pm 0.9$ & $3.5 \pm 0.8$ \\
ITR, mean \pm std. dev. & & 0.398 \\
Answer scale: $1-4$ & & 0.020 \\
\hline HD Hemodialysis, $P D$ Peritoneal dialysis, ILOC Internal locus of control, ITR Importance of taking responsibility, std. dev standard deviation
\end{tabular}

HD Hemodialysis, PD Peritoneal dialysis, ILOC Internal locus of control, ITR Importance of taking responsibility, std. dev standard deviation 
Table 2 Results of the multivariate logistic regression models on the uptake of PD (Models A and B)

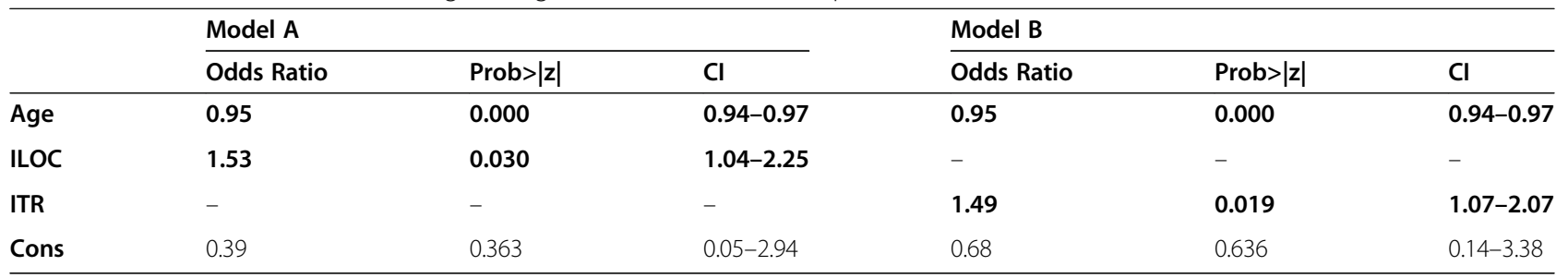

CI Confidence Interval, ILOC Internal locus of control, ITR Importance of taking responsibility, Cons constant, Prob Probability, PD Peritoneal dialysis

and B) confirm this effect. In both models, the confounder of age keeps its impact.

Both multivariate models (A and $\mathrm{B}$ ) revealed that the effect of ILOC or ITR cannot be solely explained by the younger age of the PD patients. The odds ratio of 1.53 in Model A means that people one level higher on the 5-point ILOC Likert scale have a 53\% higher chance of being in the PD group (adjusted for age). A one-levelhigher ITR on the 4-point answer scale means a $49 \%$ higher chance of being in the PD group. The effect of age is similar in both models. Comparing the odds ratios of ILOC and ITR, makes clear that they have a similar impact.

A total of 153 patients ticked N/A for ITR. They were excluded because N/A is an alternative category to the remaining Likert scale, which means that the respondent has not provided a direct answer to the particular question. Thus, the N/A response category cannot be included in an analysis using a Likert scale. However, in this context N/A could mean that taking responsibility was not an issue and therefore not important at all. The significant lower ILOC values in N/A responders in the ITR and the positive correlation between ITR and ILOC underline this assumption. Since responders who answered N/A were mainly HD patients, we assume that the effect of ITR could have been even larger if they had been included in the analysis. This has to be interpreted with caution. Hence, the chosen methodological approach offers a conservative estimation of the effect of ITR.

Although some of the previous qualitative studies did not differentiate between the dialysis modalities, they established the relevance of the desire for control when deciding between different renal replacement therapies
[23, 24]. PD patients often stressed aspects of autonomy and control that were causal for their decision [26, 27], whereas HD patients reported a loss of control because of the feeling they could not manage their life any longer [28]. This became particularly clear in quotes from semi-structured interviews [24, 26, 28, 29]. Our study, using the validated ILOC scale [19] and a larger sample $(n=630)$ is the first quantitative examination that confirms this association.

The uptake of PD is generally dependent on the socioeconomic context of the healthcare system, reimbursement policies, the PD provision by nephrologists or staff perceptions regarding a candidate's suitability for PD [34-37]. Despite the SHI reimburses all dialysis options, Germany historically shows a low PD utilization. The dialysis providers also support the uptake of PD. Hence, the framework conditions for a higher PD utilization give the impression to be in place and there seem to be other factors on the providers' level. Researchers have been trying to grasp for years, why these factors are strong drivers especially in Germany. Nevertheless, as $\mathrm{PD}$ is a home dialysis treatment that requires patients to participate and contribute, it is beneficial if patients' personalities make them suited to the treatment. Besides patients' personal conditions like poor mobility, comorbidities [38], a lack of space for PD supplies at home [39] or the involvement of partners [40], nephrologists should be aware of taking patients' personality into account to get an idea whether PD could be an option for them. A review of the barriers in dialysis modality choice showed that pre-dialysis education programs and decision aids can help to enable patients to make an autonomous and confident decision when selecting a dialysis modality [41]. The authors explain this by patients' lack

Table 3 Association of ITR with ILOC and dialysis modality

\begin{tabular}{lllll}
\hline \multirow{2}{*}{ ITR } & HD & & \multicolumn{2}{l}{ PD } \\
\cline { 2 - 5 } & $\mathbf{n}[\%]$ & Mean ILOC-values & & Mean ILOC-values \\
\hline Very important & $272[48.3]$ & 4.3 & $43[66.15]$ & 4.4 \\
Rather important & $178[31.5]$ & 3.9 & $13[20.0]$ & 3.9 \\
Not very important & $76[13.5]$ & 3.6 & $7[10.8]$ & 4.0 \\
Not important at all & $38[6.7]$ & 3.7 & $2[3.1]$ & 4.2 \\
\hline
\end{tabular}

HD Hemodialysis, ITR Importance of taking responsibility, ILOC Internal locus of control, PD Peritoneal dialysis 
of knowledge, which reduces the level of confidence and control [41]. Structured patient education programs are also associated with increased utilization of PD [4, 42, 43]. Of course, generic personality traits cannot be fundamentally changed by information or patient education, but the usage of pre-dialysis education programs could help to reduce fear and encourage patients to be autonomous and confident enough to opt for PD. At an early stage of the dialysis modality decision, this approach may enable an informed decision considering patients' personal attitudes.

\section{Strengths and limitations}

The German SHI is compulsory and its insurance companies are obliged to contract with every person and, thus, has a broad collective of insurants all over Germany [44]. Due to the cooperation with DAK-Gesundheit and SBK covering 6.6 million insurants $[31,32]$ and the high response rate of $46 \%$ this study has a representative sample with minimized risk of a selection bias.

Our study population consisted of 630 respondents out of about 75,000 German dialysis patients receiving ambulatory dialysis treatment reimbursed by the SHI [6]. The mean age in the study population $(\mathrm{HD}=69$, $\mathrm{PD}=60$ ) was marginally higher than the general dialysis patient population in Germany $(\mathrm{HD}=68, \mathrm{PD}=58)$ [6]. The proportion of women included in this analysis was similar to the national average (39.8\% vs. $39.3 \%)$ [6]. We show a lower percentage of prevalent patients dialyzing via PD in our sample (4.3\% vs. 6.1\%) [6]. The difference may be related to the fact that the basis for calculation varied. The underlying report on quality in dialysis is based on the number of conducted dialyses billed (annual prevalence). The SHIs selected their insurants on dialysis for the survey (point prevalence). Annual and point prevalence are thus difficult to compare. However, because we focus on the role of personality in decisionmaking for $\mathrm{PD}$, we assessed it as adequate to investigate the differences between HD patients and those who had primarily decided for PD, no matter if they later changed from PD to HD. The exclusion of participants choosing N/A in ITR excluded relatively more HD than PD patients. This may have led to a selection bias.

A Wilcoxon-Mann Whitney test showed N/A responders in the ITR show slight but significant lower ILOC values compared to our study population. This could indicate a limited external validity of our results, because we excluded a certain group from our study population with a significantly different attitude. Since the N/A responders in the ITR are also more likely to be HD patients, this may also confirm our assumption that the N/A category even could be treated as "not important at all". As we cannot clarify this conclusively, we assume that the N/A category has to be treated as special types of missing values that we cannot simply address with imputation techniques. Therefore, the exclusion of N/A responders were methodologically necessary to compare the effects from models A and B. Thus, we chose a conservative approach to estimating the effects and accepted the risk of a limited external validity.

In surveys, we often see a social desirability response set. Especially with the ILOC scale, the authors state this form of response bias, because personalities with a high desire to take responsibility or be assertive are desirable in a competitive society [19]. Nevertheless, there are no hints in our sample that this bias varies between HD and PD patients. If there is a general response set in the direction of high ILOC values, this is probably similar in the HD and PD groups.

The multivariate models were adjusted for age. Adjusting only for one confounder means a limited risk adjustment. There are other, patient-related and non-patientrelated factors expected to affect the uptake of PD. This is also reflected in the Pseudo $\mathrm{R}^{2}$, which shows limited predictable variance of 7 to $8 \%$, respectively. Due to the anonymous survey design, patients self-reported their information, and thus we had limited opportunities to collect all possible confounders. We examined the popular confounders of age, sex and school education. Looking at these factors, patients in our study population only varied in age. Hence, we decided to adjust only for age in our model.

\section{Conclusions}

Our analysis showed that aspects of the patients' personality play a role in the uptake of PD and should receive more attention. Participants who generally want to keep control of their lives and take responsibility for their dialysis treatment tended to choose PD. As PD is a home dialysis treatment that requires patients to participate and contribute, it is beneficial if patients' personalities make them suited to the treatment procedure. Having two completely different treatment options, which are appealing to different personalities, gives us the opportunity to consider personal attitudes in decision-making for dialysis modality.

\section{Abbreviations}

Cl: Confidence interval; DAK: Deutsche Angestellten-Krankenkasse; ESRD: Endstage renal disease; HD: Hemodialysis; ILOC: Internal locus of control;

ITR: Importance of taking responsibility; N/A: Not applicable; PD: Peritoneal dialysis; Prob: Probability; SBK: Siemens Betriebskrankenkasse; SHI: Statutory health insurance; Std. dev: Standard deviation

\section{Acknowledgements}

The authors thank all patients for their participation. Thanks to corresponding patients and nephrologists who helped us in questionnaire design, as well as Markus Alich, Alinda Reimer, Pamela Saak, Katrin Meyer and Swenja Krueppel who assisted in the data collection. The authors also thank DAK-Gesundheit und SBK for giving them the opportunity to conduct this survey. 


\section{Authors' contributions}

IS conceptualized the study, conducted the analysis and wrote the manuscript. TO was involved in the data collection and obtained ethical approval. TM provided support in light of his practical experience in PD and medical publications. He critically revised the manuscript regarding content and structure. NS designed the MAU-PD study and shared her experience with statistical computation and interpretation. All authors carefully read the manuscript regarding the consistency of content. All authors approved the final manuscript and agreed both to be personally accountable and ensure the accuracy of the work.

\section{Author's information}

Isabell Schellartz is a health economist and health services researcher from Cologne. Her PhD thesis deals with the patient's perspective on the utilization of peritoneal dialysis. Her research also focuses on comorbidities between somatic diseases and mental disorders.

\section{Funding}

The study was funded by the Federal Joint Committee's innovation fund (Funding No 01VSF16036). The funding body had no impact on data collection, analysis and interpretation or on writing the manuscript. Open Access funding enabled and organized by Projekt DEAL.

\section{Availability of data and materials}

The data support the findings of this study are available on request, with permission of the study group, DAK Gesundheit and SBK.

\section{Declarations}

\section{Ethics approval and consent to participate}

In accordance to good clinical practice and the Declaration of Helsinki, the study got its ethical approval by the ethical committee of the University Hospital of Cologne. Due to the anonymous survey design, the participants gave their informed consent to participate and publish the summarized results by completing and responding to the questionnaire. Participants were informed about this procedure in the written study information.

\section{Consent for publication}

Not applicable.

\section{Competing interests}

IS, TO and NS declare that they have no competing interests. TM received a consultant fee from Vifor and a speaker's honorarium from Fresenius Medical Care, but they did not affect the results.

\section{Author details}

'University of Cologne, Faculty of Human Sciences and Faculty of Medicine, Institute of Medical Sociology, Health Services Research and Rehabilitation Science (IMVR), Eupener Str. 129, 50933 Cologne, Germany. ${ }^{2}$ Kidney Center Wiesbaden, Wiesbaden, Germany.

\section{Received: 21 December 2020 Accepted: 8 March 2021} Published online: 24 March 2021

\section{References}

1. Wong B, Ravani P, Oliver MJ, Holroyd-Leduc J, Venturato L, Garg AX, Quinn RR. Comparison of patient survival between hemodialysis and peritoneal Dialysis among patients eligible for both modalities. Am J Kidney Dis. 2018; 71(3):344-51. https://doi.org/10.1053/j.ajkd.2017.08.028 .

2. Zhou H, Sim JJ, Bhandari SK, Shaw SF, Shi J, Rasgon SA, Kovesdy CP, Kalantar-Zadeh K, Kanter MH, Jacobsen SJ. Early mortality among peritoneal Dialysis and hemodialysis patients who transitioned with an optimal outpatient start. Kidney Int Rep. 2019;4(2):275-84. https://doi.org/10.1016/j. ekir.2018.10.008

3. Jung H-Y, Jeon Y, Park Y, Kim YS, Kang S-W, Yang CW, Kim NH, Choi JY, Cho $J H$, Park SH, Kim CD, Kim YL. Better quality of life of peritoneal Dialysis compared to hemodialysis over a two-year period after Dialysis initiation. Sci Rep. 2019;9(1):10266. https://doi.org/10.1038/s41598-019-46744-1 .

4. de Fijter CWH, van Diepen ATN, Amiri F, Dekker FW, Krediet RT. Patientreported outcomes (PROs) argue against the limited use of peritoneal dialysis in end-stage renal disease. Clin Nephrol. 2018;90(2):94-101. https:// doi.org/10.5414/CN109369

5. Wong CKH, Chen JY, Fung SKS, Lo WK, Lui SL, Chan TM, et al. Health-related quality of life and health utility of Chinese patients undergoing nocturnal home haemodialysis in comparison with other modes of dialysis. Nephrology (Carlton). 2019;24:630-7.

6. Potthoff F, Münscher C, Berendes A, Weber W. Annual report about the quality in dialysis 2017. [Jahresbericht 2017 zur Qualität in der Dialyse]; 2018.

7. National Association of Statutory Health Insurance Funds. Statutory health insurance. 2020. https://www.gkv-spitzenverband.de/english/statutory_hea Ith_insurance/statutory_health_insurance.jsp.

8. National Association of Statutory Health Insurance Physicians. Doctor's fee scale: 3rd quarter 2017. [Einheitlicher Bewertungsmaßstab (EBM): Stand: 3. Quartal 2017] 2017.

9. German Civil Code. Obligation for information. [Aufklärungspflichten]. § 630e Abs. 1 Satz 3. Available at https://www.gesetze-im-internet.de/bgb/_ 630e.html.

10. Lameire N, van Biesen W. Epidemiology of peritoneal dialysis: a story of believers and nonbelievers. Nat Rev Nephrol. 2010;6(2):75-82. https://doi. org/10.1038/nrneph.2009.210.

11. Francois K, Bargman JM. Evaluating the benefits of home-based peritoneal dialysis. Int J Nephrol Renov Dis. 2014;7:447-55. https://doi.org/10.2147/ IJNRD.S50527.

12. Chiang P-C, Hou J-J, Jong I-C, Hung P-H, Hsiao C-Y, Ma T-L, Hsu Y-H. Factors associated with the choice of peritoneal Dialysis in patients with end-stage renal disease. Biomed Res Int. 2016;2016:5314719.

13. Robinski M, Mau W, Wienke A, Girndt M. The Choice of Renal Replacement Therapy (CORETH) project: Dialysis patients' psychosocial characteristics and treatment satisfaction. Nephrol Dial Transplant. 2017;32(2):315-24. https:// doi.org/10.1093/ndt/gfv464.

14. Wang $\mathrm{I}-\mathrm{K}$, Lin C-L, Yen T-H, Lin S-Y, Sung F-C. Comparison of survival between hemodialysis and peritoneal dialysis patients with end-stage renal disease in the era of icodextrin treatment. Eur J Intern Med. 2018;50:69-74. https://doi.org/10.1016/j.ejim.2017.11.017

15. Sun C-Y, Sung J-M, Wang J-D, Li C-Y, Kuo Y-T, Lee C-C, Wu JL, Chang YT. A comparison of the risk of congestive heart failure-related hospitalizations in patients receiving hemodialysis and peritoneal dialysis - a retrospective propensity score-matched study. PLoS One. 2019;14(10):e0223336. https:// doi.org/10.1371/journal.pone.0223336.

16. Marin JG, Beresford L, Lo C, Pai A, Espino-Hernandez G, Beaulieu M. Prescription patterns in Dialysis patients: differences between hemodialysis and peritoneal Dialysis patients and opportunities for Deprescription. Can J Kidney Health Dis. 2020;7:2054358120912652.

17. Lee SW, Lee NR, Son SK, Kim J, Sul AR, Kim Y, et al. Comparative study of peritoneal dialysis versus hemodialysis on the clinical outcomes in Korea: a population-based approach. Sci Rep. 2019;9:1-7.

18. Rotter JB. Generalized expectancies for internal versus external control of reinforcement. Psychol Monogr Gen Appl. 1966;80(1):1-28. https://doi.org/1 $0.1037 /$ h0092976

19. Jakoby N, Jacob R. Measuring the internal and external locus of control in general population surveys. [Messung von internen und externen Kontrollüberzeugungen in allgemeinen Bevölkerungsumfragen]. ZUMA Nachrichten. 1999;23:61-71.

20. Stevens NR, Adams N, Wallston KA, Hamilton NA. Factors associated with women's desire for control of healthcare during childbirth: psychometric analysis and construct validation. Res Nurs Health. 2019;42(4):273-83. https://doi.org/10.1002/nur.21948 .

21. McGovern M, Kernan R, O'Neill MB. Parental decisions regarding pre-hospital therapy and costing of the emergency department visit. Ir Med J. 2017;110: 513.

22. Shabason JE, Mao JJ, Frankel ES, Vapiwala N. Shared decision-making and patient control in radiation oncology: implications for patient satisfaction. Cancer. 2014;120(12):1863-70. https://doi.org/10.1002/cncr.28665

23. Gordon EJ. Patients' decisions for treatment of end-stage renal disease and their implications for access to transplantation. Soc Sci Med. 2001;53(8):97187. https://doi.org/10.1016/S0277-9536(00)00397-X

24. Han E, Haldane V, Koh JJK, Quek RYC, Ozdemir S, Finkelstein EA, Jafar TH, Choong HL, Gan S, Lim LWW, Shiraz F, Legido-Quigley H. Perspectives on decision making amongst older people with end-stage renal disease and caregivers in Singapore: a qualitative study. Health Expect. 2019;22(5):110010. https://doi.org/10.1111/hex.12943 
25. Murray MA, Brunier G, Chung JO, Craig LA, Mills C, Thomas A, Stacey D. A systematic review of factors influencing decision-making in adults living with chronic kidney disease. Patient Educ Couns. 2009;76(2):149-58. https:// doi.org/10.1016/j.pec.2008.12.010

26. Wuerth DB, Finkelstein SH, Schwetz O, Carey H, Kliger AS, Finkelstein FO. Patients' descriptions of specific factors leading to modality selection of chronic peritoneal dialysis or hemodialysis. Perit Dial Int. 2002;22(2):184-90. https://doi.org/10.1177/089686080202200204 .

27. Habib A, Durand A-C, Brunet P, Duval-Sabatier A, Moranne O, Bataille S, Benhaim L, Bargas É, Gentile S. Factors affecting the choice of peritoneal dialysis: perspective of patients and nephrologists. [Facteurs influençant le choix de la dialyse péritonéale: le point de vue des patients et des néphrologues]. Nephrol Ther. 2017;13(2):93-102. https:/doi.org/10.1016/.jnephro.2016.07.451 .

28. Lin C-C, Lee B-O, Hicks FD. The phenomenology of deciding about hemodialysis among Taiwanese. West J Nurs Res. 2005;27(7):915-29; discussion 930-4. https://doi.org/10.1177/0193945905278390.

29. Holvoet E, Verhaeghe S, Davies S, Combes G, François K, Johnson D, et al. Patients' experiences of transitioning between different renal replacement therapy modalities: a qualitative study. Perit Dial Int. 2020;40(6):548-55. https:// doi.org/10.1177/0896860819896219.

30. Tweed AE, Ceaser K. Renal replacement therapy choices for pre-dialysis renal patients. Br J Nurs. 2005;14:659-64. https://doi.org/10.12968/bjon.2005.14.12.18287 .

31. DAK. About us. [Über uns] 2020. https://www.dak.de/dak/unternehmen/ ueber-uns-2091798.html\#/.

32. SBK. Profile [Profil] 2020. https://www.sbk.org/unternehmen-sbk/profil/.

33. Scholten N, Ohnhaeuser T, Schellartz I, von Gersdorff G, Hellmich M, Karbach U, Pfaff H, Samel C, Stock S, Rascher K, Mettang T. Multidimensional analysis of factors responsible for the low prevalence of ambulatory peritoneal dialysis in Germany (MAU-PD): a cross-sectional mixed-methods study protocol. BMJ Open. 2019;9(4):e025451. https://doi.org/10.1136/bmjopen-2018-025451

34. Tennankore KK, Hingwala J, Watson D, Bargman JM, Chan CT. Attitudes and perceptions of nephrology nurses towards dialysis modality selection: a survey study. BMC Nephrol. 2013;14(1):192. https://doi.org/10.1186/1471-23 69-14-192.

35. Bouvier N, Durand P-Y, Testa A, Albert C, Planquois V, Ryckelynck J-P, Lobbedez T. Regional discrepancies in peritoneal dialysis utilization in France: the role of the nephrologist's opinion about peritoneal dialysis. Nephrol Dial Transplant. 2009;24:1293-7.

36. Choy AS-M, Li PK-T. Sustainability of the peritoneal Dialysis-first policy in Hong Kong. Blood Purif. 2015;40(4):320-5. https://doi.org/10.1159/000441 580 .

37. Jain AK, Blake P, Cordy P, Garg AX. Global trends in rates of peritoneal dialysis. J Am Soc Nephrol. 2012;23(3):533-44. https://doi.org/10.1681/ASN.2 011060607

38. Rosansky SJ, Schell J, Shega J, Scherer J, Jacobs L, Couchoud C, Crews D, McNabney $M$. Treatment decisions for older adults with advanced chronic kidney disease. BMC Nephrol. 2017;18(1):200. https://doi.org/10.1186/s12882-017-0617-3 .

39. Sukul N, Zhao J, Fuller DS, Karaboyas A, Bieber B, Sloand JA, et al. Patient-reported advantages and disadvantages of peritoneal dialysis: results from the PDOPPS. BMC Nephrol. 2019;20(1):116. https://doi.org/10.1186/s12882-019-1304-3 .

40. Zee J, Zhao J, Subramanian L, Perry E, Bryant N, McCall M, Restovic Y, Torres $\mathrm{D}$, Robinson BM, Pisoni RL, Tentori F. Perceptions about the dialysis modality decision process among peritoneal dialysis and in-center hemodialysis patients. BMC Nephrol. 2018;19(1):298. https://doi.org/10.1186/ s12882-018-1096-X.

41. Cassidy BP, Getchell LE, Harwood L, Hemmett J, Moist LM. Barriers to education and shared decision making in the chronic kidney disease population: a narrative review. Can J Kidney Health Dis. 2018;5: 2054358118803322.

42. Devoe DJ, Wong B, James MT, Ravani P, Oliver MJ, Barnieh L, Roberts DJ, Pauly R, Manns BJ, Kappel J, Quinn RR. Patient education and peritoneal Dialysis modality selection: a systematic review and meta-analysis. Am J Kidney Dis. 2016;68(3):422-33. https://doi.org/10.1053/j.ajkd.2016.02.053 .

43. Schanz M, Ketteler M, Heck M, Dippon J, Alscher MD, Kimmel M. Impact of an in-hospital patient education program on choice of renal replacement modality in unplanned Dialysis initiation. Kidney Blood Press Res. 2017:42(5): 865-76. https://doi.org/10.1159/000484531.

44. Federal Ministry of Health. Obligation to contract. [Kontrahierungszwang] 2020. https://www.bundesgesundheitsministerium.de/service/begriffe-von-az/k/kontrahierungszwang.html.

\section{Publisher's Note}

Springer Nature remains neutral with regard to jurisdictional claims in published maps and institutional affiliations.

\section{Ready to submit your research? Choose BMC and benefit from:}

- fast, convenient online submission

- thorough peer review by experienced researchers in your field

- rapid publication on acceptance

- support for research data, including large and complex data types

- gold Open Access which fosters wider collaboration and increased citations

- maximum visibility for your research: over $100 \mathrm{M}$ website views per year

At BMC, research is always in progress.

Learn more biomedcentral.com/submissions 